\title{
Experimental Study of Automated Car Power Window with "Preset" Position
}

\author{
${ }^{1}$ Muazzin Mupit and $*^{2}$ Amir Akramin Shafie \\ ${ }^{1}$ University Kuala Lumpur Malaysia France Institute 43650 Selangor, Malaysia \\ $*^{2}$ Kulliyah of Engineering International Islamic University 53100 Kuala Lumpur, Malaysia
}

\begin{abstract}
In today's automotive industry, many features are added in power window system. For instance, Anti Trap System, with immediate reversal of the window in the event of entrapment. Thus, it gives full and reliable protection for children's hand, neck and any obstacles as well. The aim of this paper is to develop an innovative mechanism to enable the user to control the degree of opening power window position with preset position. This experiment involved design and development of PIC program, electronic circuit design and modification on existing power window mechanism. In this experiment, microcontroller PIC16F877A is applied as a medium to achieve the goal. Generally, it will control the degree opening window whenever the user or motorist required, plus anti-entrapment features on window lifting control system. Therefore the user will be able to open and close the power window within the selected position and feel free while maneuvering their vehicles.
\end{abstract}

Keywords: Car power window, Anti trap mechanism, Innovation

\section{Introduction}

There are a lot of innovative mechanisms which related to the power window system where initially introduced by Pakard in 1940 [1]. For instance the innovation, pioneered by Nissan at about the same time, is the express-down window which allows the window to be fully lowered with one tap on the switch, as opposed to holding the switch down until the window retracts [2]. Since that, the safety has taken into account to avoid someone unintentionally stuck within the power window and the frame which may cause fatal accident. Therefore, several methods are invented on the anti-trap mechanism.

Based on the idea of Kurihara et al., the power window is adapted to become operative when the ignition switch off [3] and it is followed by Chen et al. where the window glass will stop moving when an obstacle detected [4]. Another mechanism which studied by Luebke et al. and Miller et al. are based on deformation of sensing edges when obstruction occurred [5], [6]. For Butler et al., he studied the antitrap on the trunk lid [8] but still used the Luebke et al. [5] weather-strip design. Instead of locating the antitrap sensor at weather-strip, Shank et al. allocate the infrared sensor as an anti-trap system just next to the rear mirror [9].
From the review, it shows that most of the research studies focus on the anti-trap mechanism. Therefore in this study, the power window positioning system is added to be a part of innovative idea. As shown in Figure 1.0, the power window system controlled by microcontroller [10] unit divided into two modes; manual and auto. In 'manual mode', opening and closing of power window is just like the usual passenger car. In common 'auto mode' the power window operates to be fully opened or fully closed. Whereas in 'auto mode' with preset button, the user is able to set the degree of window opening at any desired position.

In both common 'manual' and 'auto' modes, the upper and lower limit of power window was set in default position in order to prevent the over current flow on the motor coil which might ruin the motor itself and window regulator.

\section{Materials and Method}

The methodologies for the system development are divided into hardware and software development. The development of hardware and software comprises the modification on existing power window (Malaysia national car), circuit design development and program development.

*Corresponding author: Depart. of Industrial Automation, Universiti Kuala Lumpur-Malaysia France Institute, 43560, MALAYSIA. E-mail: muazzin@ mfi.unikl.edu.my, Phone: +60132086063 Fax: +60389258845 


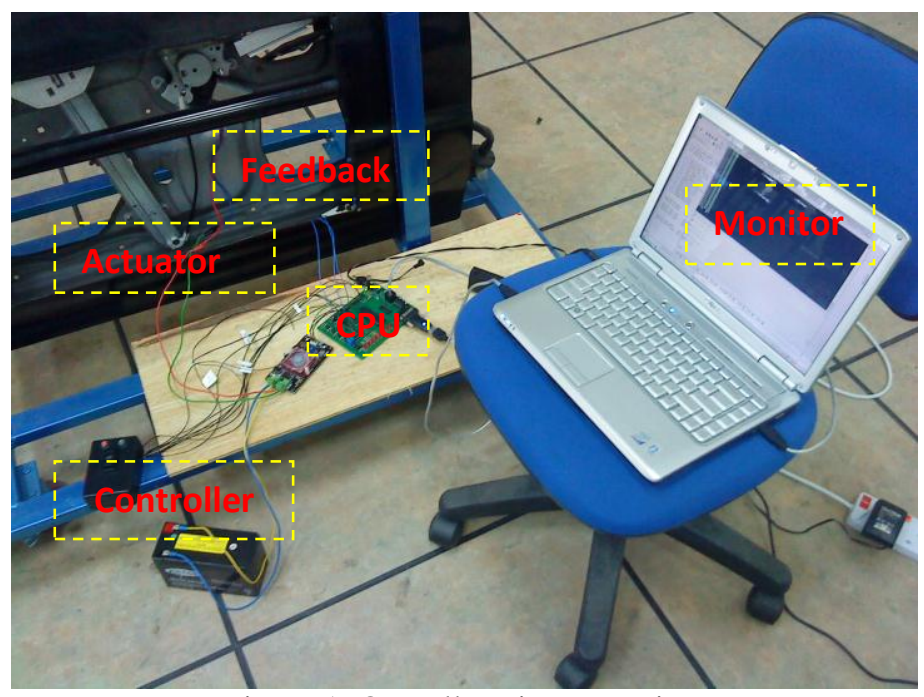

Figure 1. Overall project overview

After all hardware and software developments are completed, the circuit integration was done. Finally the analysis of result and measurement data was taken.

\subsection{Method of Control}

The method for controlling the power window defined as below:

\subsubsection{Manual Mode}

The controller button is able to control the power window up or down as the user desired.

\subsubsection{Automatic Mode}

$i$. Without preset position mode: The user is able to fully open and fully close the power window.

When an obstruction occurred during the window is moving up, the anti-trap is activated to reverse the window's motor.

ii. With Preset position mode: The user is able to open the window to their desired position. The user is required to:

Set the limit as to where the window glass need to be opened as shown in Figure 2.

Now, the power window will go up and down within that desired position only as in Figure 3. Hence, the user will be able to focus on maneuvering the vehicle without worrying about the power window position anymore.

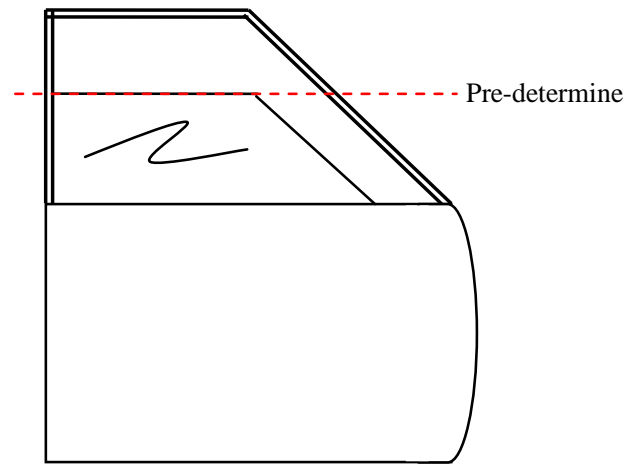

Figure 2. Pre-determined positions

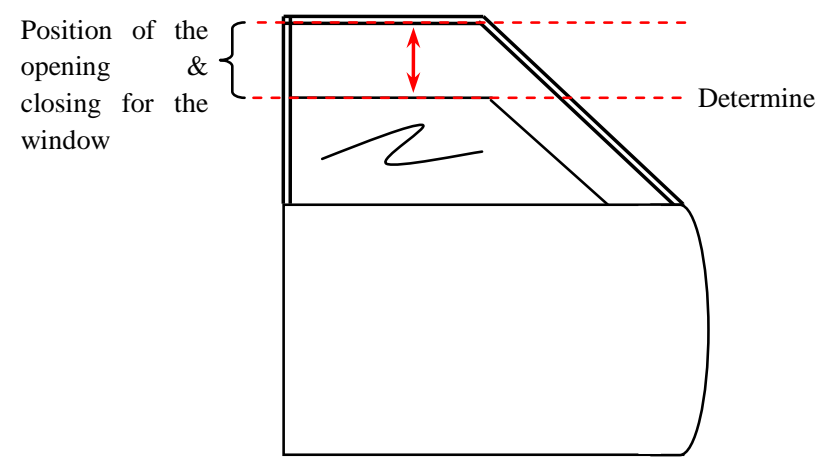

Figure 3. Positioning for the window opening and closing

\subsection{Anti-trap deformation force}

The anti-trap or anti-pinch sensor is embedded in the weather strip. This sensor is made by two conducting materials and embedded in the profile of the thermoplastic deflectable casing. When an obstruction occurs while the glass window is moving up, the two 
conductive materials are contacted see Figure 4. Therefore electrical control signal is activated and sent the signal to the controller to lower the window. This form of thermo-plastic will deform when the force applied within $60 \mathrm{~N}$ to $100 \mathrm{~N}$.

According to the formula: $F=m g$ where; $g=9.81$ $\frac{m}{s^{2}}$ and $m=$ mass

Since;

$$
1 N=1 \mathrm{~kg} \frac{\mathrm{m}}{\mathrm{s}^{2}}
$$

Therefore;

$$
\begin{gathered}
60 \mathrm{~kg} \frac{m}{\mathrm{~s}^{2}}=m * 9.81 \frac{\mathrm{m}}{\mathrm{s}^{2}} \\
\text { mass }=\frac{60}{9.81} \mathrm{~kg} \quad \therefore \text { mass }=6.12 \mathrm{~kg}
\end{gathered}
$$

When the force is converted to mass, the pinching weight is within $6.12 \mathrm{~kg}$ up to $10.2 \mathrm{~kg}$ for the sensor to detect and response to the presence of the obstacle.

\subsection{Design Mechanism}

This system is illustrated in Figure 5 and divided into 4 major elements; where monitoring process used CCS software under Serial Input/Output Monitor display, controller part for control and program of the

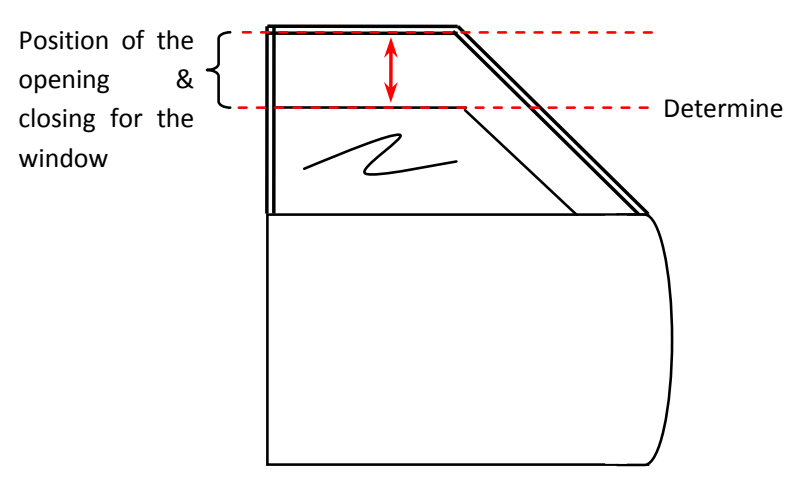

power window motor, feedback for distance measurement sensor and anti-trap function and actuator i.e. power window moving mechanism.
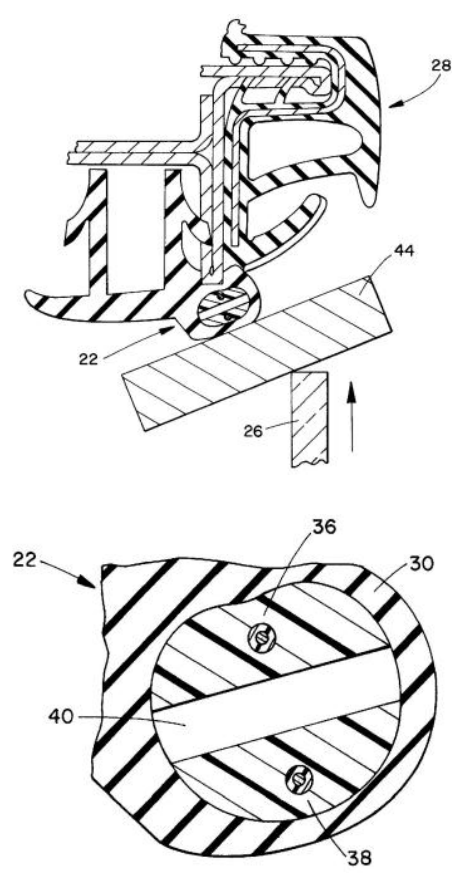

Figure 4. Obstruction graphical simulation and sensing element close-up [5].

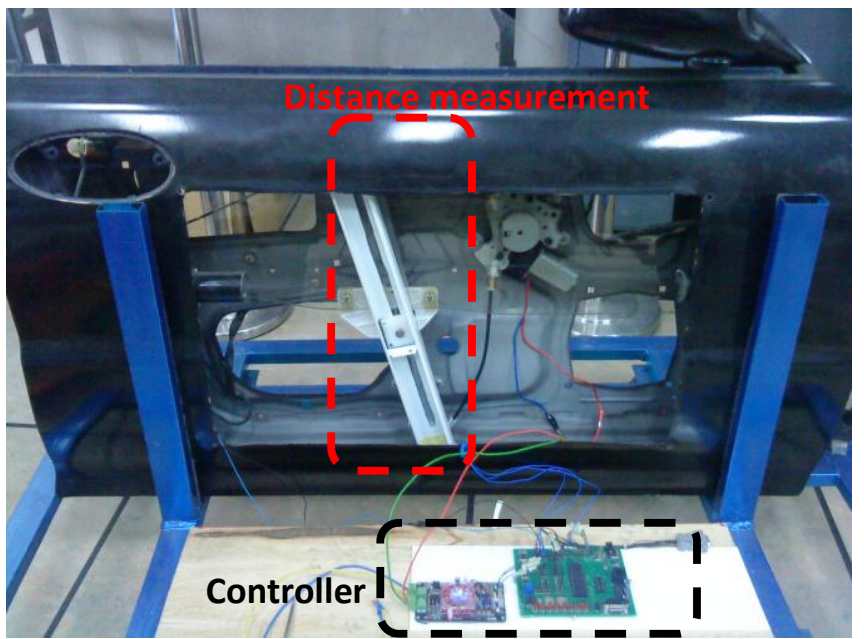

Figure 5. Graphical illustration and actual project assembly 


\subsubsection{Distance Measurement Sensor}

To avoid the unnecessary problem, the General Purpose Type Distance measuring sensors GPD12 Figure 6 and Figure 7 has been chosen to be an appropriate sensing element to be applied to this project. This sensor consists of several features which are; less influence on the color of reflective objects, input voltage is $5 \mathrm{~V}$ where producing an analogue voltage output from $2.4 \mathrm{~V}$ to $0.4 \mathrm{~V}$ proportionally with the distance measured, high accuracy measuring by sequential position detection and mean processing data output, detecting distance from $10 \mathrm{~cm}$ to $80 \mathrm{~cm}$, with low voltage applied and also low cost in price; see Figure 8.

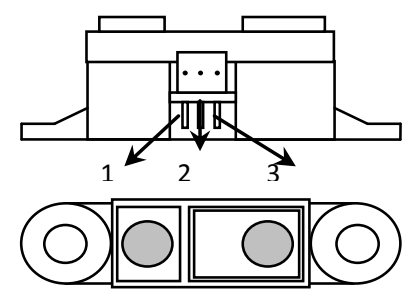

Legend:

$1-\mathrm{V}$ output $=5 \mathrm{~V}$

$2-$ Ground

$3-\mathrm{Vcc}=5 \mathrm{~V}$

Figure 6. GP2D12 sensor
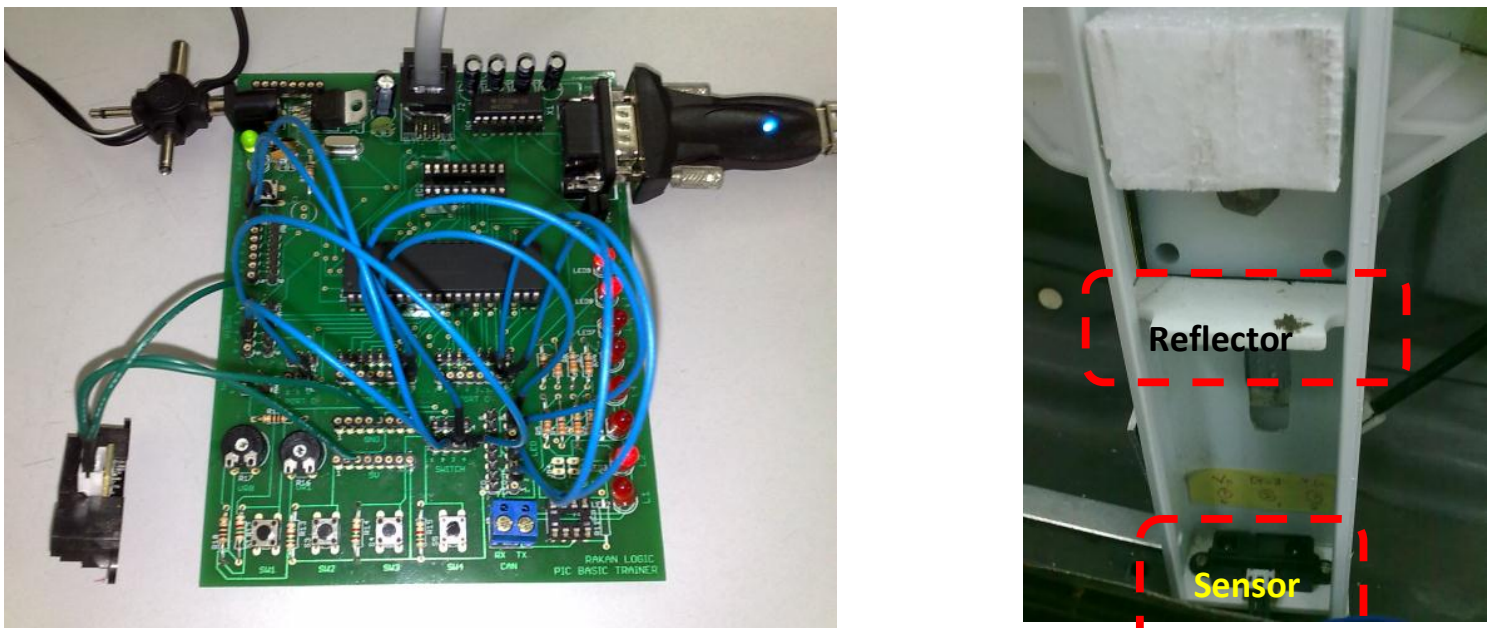

Figure 6. GP2D12 tested on the PIC board and power window regulator

\subsubsection{Measurement data \& plotted graph}

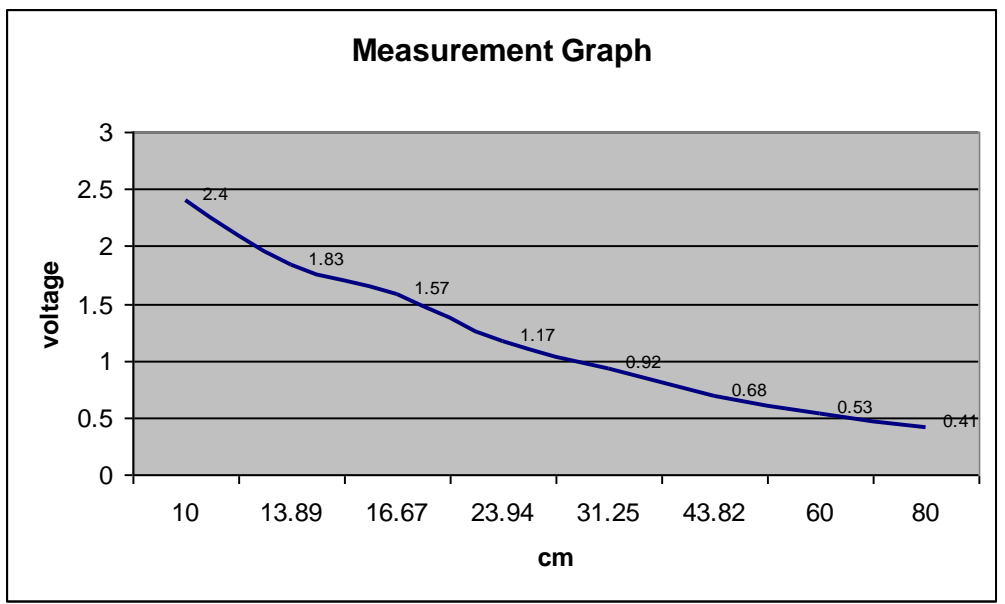

Figure 7. Experimental result 
Table 1. Measurement data

\begin{tabular}{|c|c|c|c|c|c|c|c|c|}
\hline Point & A & B & C & D & E & F & G & H \\
\hline cm & 10 & 13.89 & 16.67 & 23.94 & 31.25 & 43.82 & 60 & 80 \\
\hline voltage & 2.4 & 1.83 & 1.57 & 1.17 & 0.92 & 0.68 & 0.53 & 0.41 \\
\hline
\end{tabular}

\subsection{Schematic Diagram Development}

To develop the schematic diagram, the ExpressSCH CAD software has been used in Windows application for drawing schematics Figure 9 and the integrated control system block diagram shown in Figure 10. This circuit directly applied 12 Volt DC.

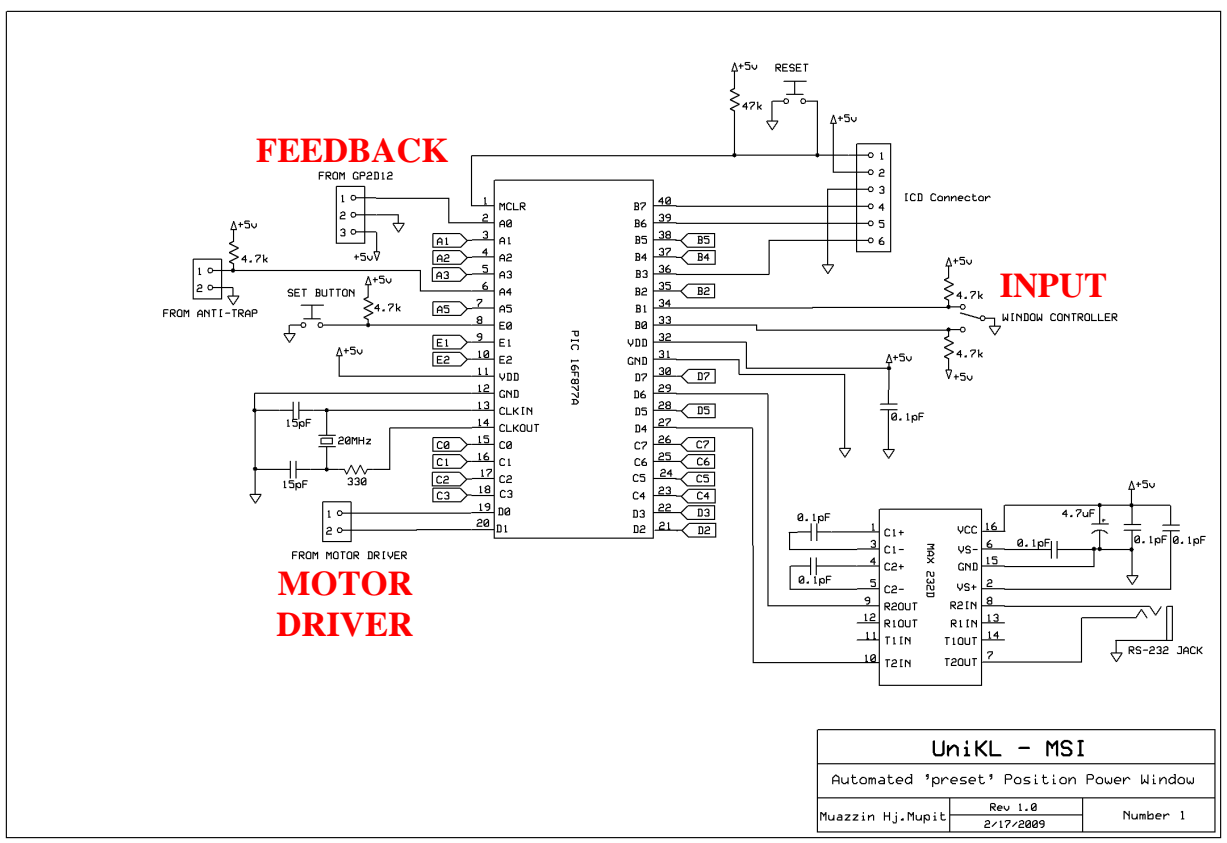

Figure 9. Schematics diagrams and integrated block diagram

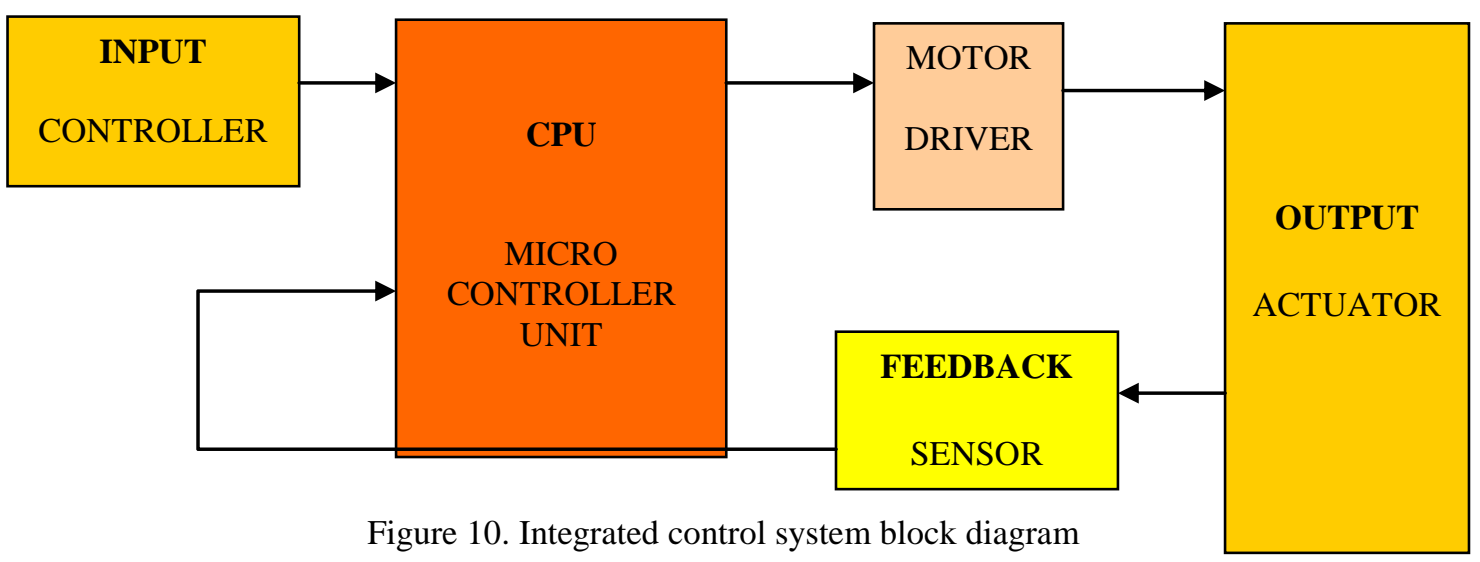

\section{Results}

To identify the performance of this system, the Kaptoris Data Acquisition System (DAQ) is used to monitor the movement and variation of each signal in terms of sensor, button up and button down movement. Kaptoris DAQ system displayed the data input from sensor and both button up and down. Shown in Figure 11 and Figure 12, is the integration of power window regulator and Kaptoris DAQ system. 


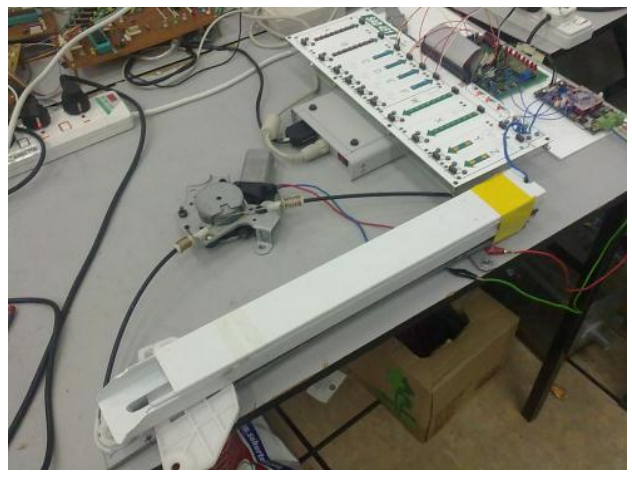

Figure 11. Overview of Kaptoris DAQ system and power window regulator

In Figure 13, it shows the combination of these three modes with respect to the button up and button down in duration of 30 seconds. It shows that in:-

Manual mode : Windows move according to the button pressed.

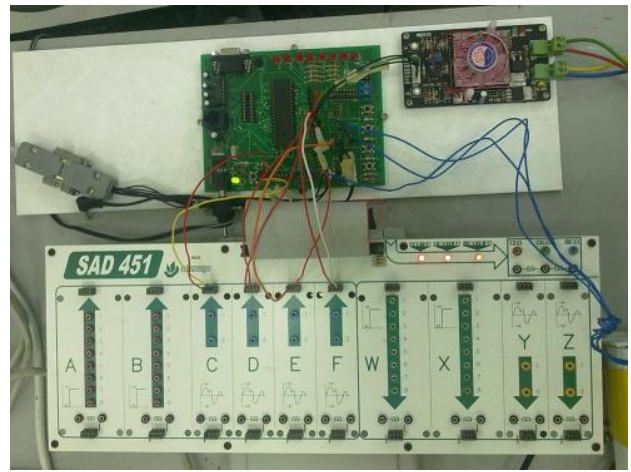

Figure 12. Kaptoris DAQ systems

Preset mode : Constant variation of upper limit $1.05 \mathrm{~V}$ and lower limit $2.00 \mathrm{~V}$

Auto mode : Constant variation of maximum upper limit $0.6 \mathrm{~V}$ and maximum lower limit $2.20 \mathrm{~V}$

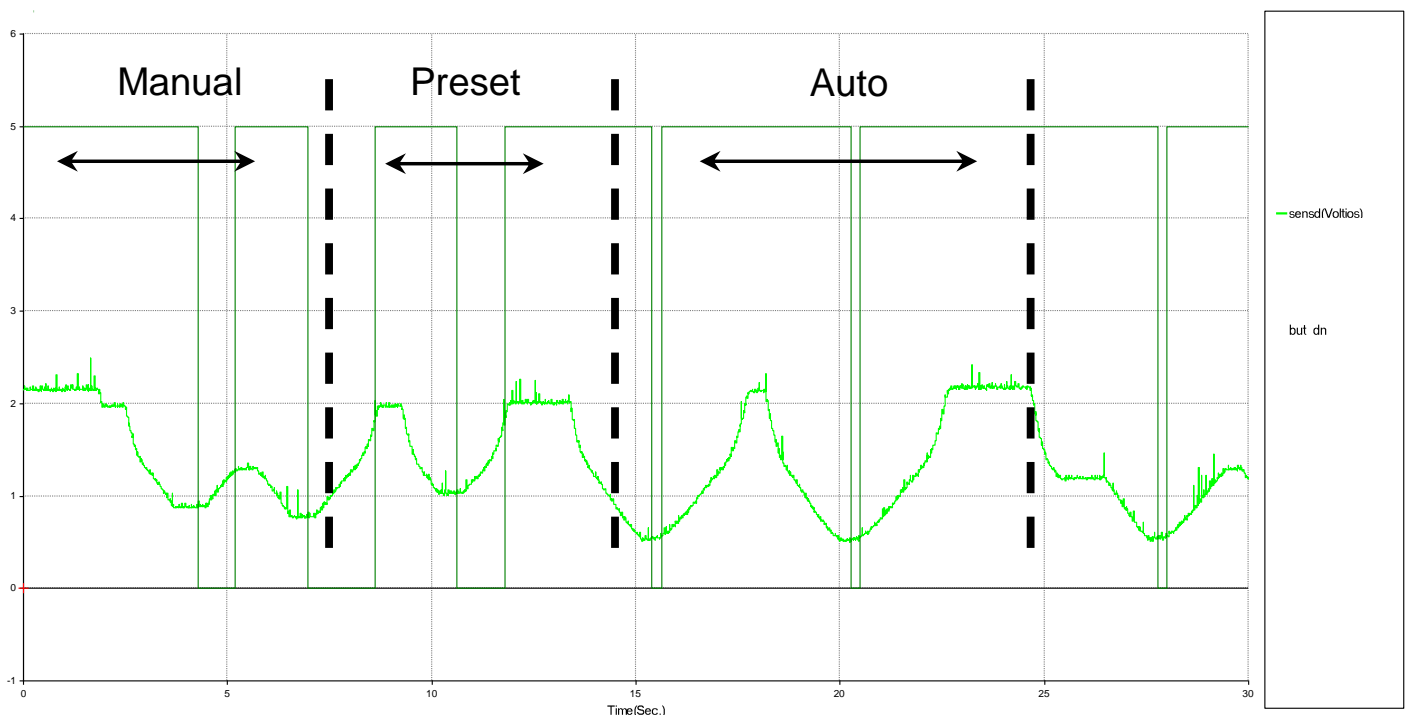

Figure 13. Manual - preset -Auto modes graphical simulation

\section{Discussion}

During the full experiment, it is observed that the power window motor is unable to fully close and an intermittent gap occur due to the alignment of sensor and reflector. The problem encounter on the reflector's position itself, where it is not perpendicular with the sensor due to the reflector's position which only attached at the window glass. As a solution, the sensor needs to be placed in one casing where the reflector will move accordingly with the track i.e. linear guide. Therefore the linear guide was fabricated to ensure that the sensor position perpendicular with the reflector. After it is tested, the repeatability is good based on repeated experiment. But unfortunately when the window is closed, it left a gap about $5 \mathrm{~cm}$ but much better than previous experiment. This occurred due to severe consequences where either the reflector's angle is $>$ $90^{\circ}$ or $<90^{\circ}$ as shown in Figure 14. 

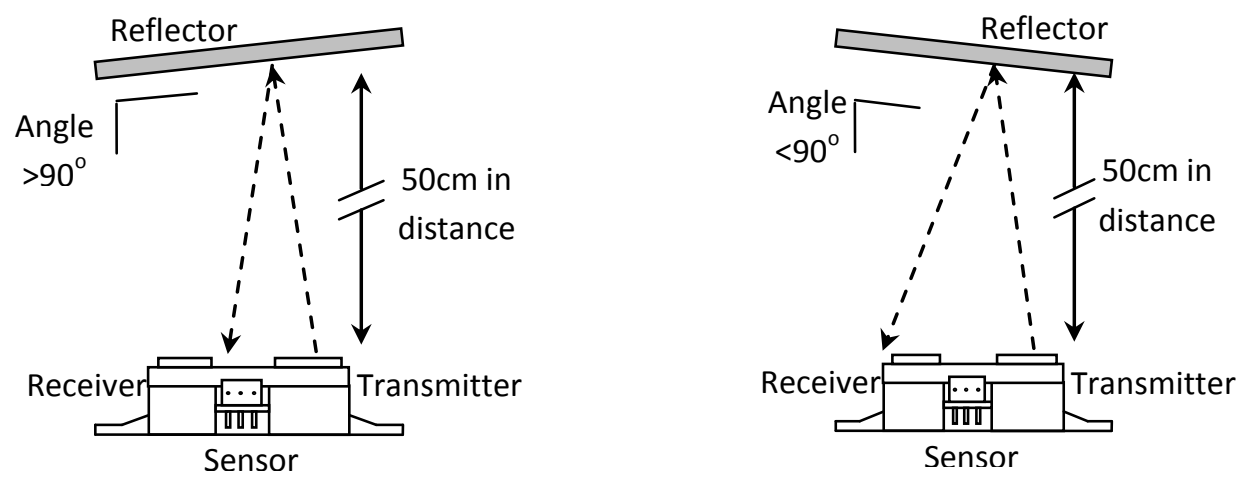

Figure 14. Reflector's illustration due to manual fabrication on the reflector's track in a farthest distance

On the downward position, it is unable to make it fully open due to the sensor GP2D12 characteristic

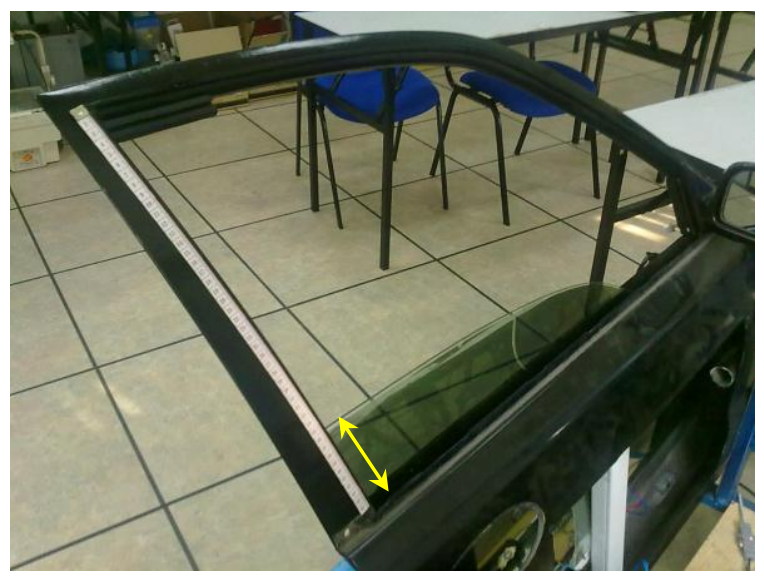

which only can detect as close as $10 \mathrm{~cm}$ [11] of distance as shown in Figure 15.

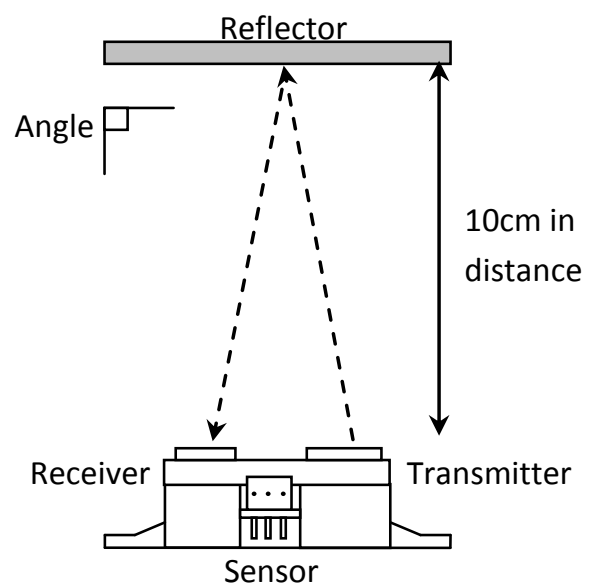

Figure 15. Power window fully opened and graphic illustration

\section{Conclusions}

In terms of repeatability, the system mechanism is able to get to the same position after some modification and alignment made to the experimental rig. In AUTO MODE the up and down window is move accordingly to the degree of opening window. This is because the sensors detect the incoming reflective signal accurately, but not on the closing window. This is occurred because the reflective signal diffused when the reflector panel is farther away from the sensor. This error occurred mostly during the MANUAL MODE, where the signal in closing window is intermittent. Therefore with this innovative idea, I hope it will contribute to so many upcoming innovations in the future.

\section{References}

[1] Ward, James Arthur. The Fall of Pakard Motor Car Company. Stanford University Press 1995. ISBN: 978-0-8047-2457-9

[2] http://www.autoaccessories.in/Auto-Parts.php?q= $42 \& \mathrm{~d}=$ Power\% $\%$ window

[3] Kurihara et al. (Aug. 20, 1985). Apparatus for Controlling Power Window of Vehicle. Patent No.: 4,536,687

[4] Chen (Aug. 15, 1995). Safety Power Window Mechanism for All Types Automobile. Patent No.: 5440944

[5] Luebke et al. (Sept. 7, 1999). Auto Window Switch And Obstacle Detect/Protect With Override. Patent No.: 5949207

[6] Miller et al. (Nov. 10, 1998). Sensing Edge. Patent No: 5832665

7] Bledin (Jan.8, 2002). Capacitive Anti Finger Trap 
Proximity Sensor. Patent No.: US6337549 B1.

[8] Butler et al. (Oct.2, 2001). Pinch Sensing Arrangement For A Motor Vehicles Power Liftgate. Patent No.: 6397605 B1.

[9] Shank et al. (March 27, 2003). Anti-Entrapment System. Patent No.: US2003/0056600 A1

[10] Han-Way Huang (2005). PIC Microcontroller: An Introduction to Software \& Hardware Interfacing, Thomson Delmar Learning, ISBN 1-4018-3967-3
[11] DataSheet-GP2D12 (12 January 2005). http://www.active-robots.com/products/sensorssharp.shtml accessed on 5 January 2009 [12] Microchip Technology Inc. (2006). Anti-Pinch Window Lift Control Module User's Guide, pp. 5 10. 